\title{
EFEITOS DA TEMPERATURA E DA DEFESA DA PRESA NO CONSUMO PELO PREDADOR SUPPUTIUS CINCTICEPS (STÄL) (HETEROPTERA:PENTATOMIDAE) ${ }^{1}$
}

\author{
FRANCISCO ROBERTO DE AZEVEDO² e FRANCISCO DE SOUSA RAMALHO ${ }^{3}$
}

\begin{abstract}
RESUMO - A pesquisa objetivou determinar se a temperatura e a defesa da presa afetam o consumo e a utilização de larvas de Tenebrio molitor L. por ninfas de Supputius cincticeps (Stäl). Quantificaram-se em cada um dos ínstares do predador Supputius cincticeps os consumos bruto e diário das larvas de T. molitor com e sem defesa, ganho de peso total e ganho de peso diário pelo predador. Foram determinados os efeitos da defesa da presa e da temperatura ambiente no consumo de alimento pelas ninfas de $2^{\circ}, 3^{\circ}, 4^{\circ}$ e $5^{\circ}$ ínstares de $S$. cincticeps. A pesquisa foi conduzida na Unidade de Controle Biológico da Embrapa-Centro Nacional de Pesquisa de Algodão, em Campina Grande, PB, a 20, 25, e $30^{\circ} \mathrm{C}$, $60 \pm 10 \%$ UR e fotofase de 14 horas. Os resultados mostraram que o consumo bruto de larvas de T. molitor pelo $S$. cincticeps depende do ínstar do predador e da temperatura, do ínstar do predador e da defesa da presa, e da temperatura e defesa da presa; o consumo diário de $S$. cincticeps depende do ínstar do predador e da temperatura, e do ínstar do predador e da defesa da presa, e o ganho de peso de $S$. cincticeps depende do seu ínstar, da temperatura e da defesa apresentada pelas larvas de T. molitor. O tamanho das larvas de T. molitor funciona como defesa ao ataque de $S$. cincticeps.
\end{abstract}

Termos para indexação: controle biológico, nutrição, consumo de alimento, utilização de alimento.

\author{
EFFECTS OF TEMPERATURE AND OF THE PREY DEFENSE ON THE CONSUMPTION \\ BY THE PREDATOR SUPPUTIUS CINCTICEPS (STÄL) (HETEROPTERA:PENTATOMIDAE)
}

\begin{abstract}
The objective of the research was to determine if the temperature and pray defense affect the consumption and utilization of Tenebrio molitor L. larvae by nymphs of Supputius cincticeps (Stäl). The gross and daily consumptions of $T$. molitor larvae with and without defense by the predator Supputius cincticeps, and the gross and daily weight gains of the predator were quantified. Effects of the prey defense and temperature on the food consumption by the $2^{\text {nd }}, 3^{\text {rd }}, 4^{\text {th }}$ and $5^{\text {th }}$ instar nimphs of $S$. cincticeps were determined. The research was carried out in the Biological Control Unit of the Embrapa-Centro Nacional de Pesquisa de Algodão, at Campina Grande, PB, Brazil, at 20, 25, and $30^{\circ} \mathrm{C}$, $60 \pm 10 \% \mathrm{RH}$ and $14 \mathrm{~L}: 10 \mathrm{D}$ photoperiod. The results showed that the gross consumption of $T$. molitor larvae by $S$. cincticeps depends on the predator instar and on temperature, on the predator instar and on the prey defense, and on temperature and on the prey defense; the daily consumption of $S$. cincticeps depends on its instar and on temperature, and on its instar and on the prey defense; and $S$. cincticeps weight gain depends on its instar, on temperature and on the prey defense. The size of T. molitor larvae works as a defense to attack of $S$. cincticeps.
\end{abstract}

Index terms: biological control, nutrition, food intake, food utilization.

${ }^{1}$ Aceito para publicação em 2 de junho de 1998. Pesquisa financiada pela EMBRAPA, CAPES e CNPq.

${ }^{2}$ Eng. Agr., M.Sc., Bolsista da CAPES junto à UFRPE e Embrapa-Centro Nacional de Pesquisa de Algodão (CNPA), Caixa Postal 174, CEP 58107-720 Campina Grande, PB.

${ }^{3}$ Eng. Agr., Ph.D., Unidade de Controle Biológico/Embrapa-CNPA. Bolsista do CNPq. E-Mail: framalho@cnpa.embrapa.br

\section{INTRODUÇÃO}

Os percevejos predadores atuam com eficiência no controle de pragas desfolhadoras, e este comportamento vem despertando a atenção dos pesquisadores que passaram a considerá-los como mais um dos agentes promissores no controle biológico. No entanto, a racionalidade do controle biológico está 
no restabelecimento de equilíbrio do complexo predador-presa, próximo aos níveis dos sistemas naturais e dentro do contexto da maximização da produção (Horn, 1988). Para isso são necessários estudos sobre o potencial dos predadores no controle de pragas-chave, para que possam ser integrados ao sistema de manejo de pragas (Gravena \& Cunha, 1991).

Pesquisa conduzida com Supputius cincticeps (Stäl) (Zanuncio et al., 1993) foi realizada visando gerar conhecimentos sobre a maneira de viabilizar a sua criação em laboratório. Estudos sobre a quantidade de alimento que as ninfas de $S$. cincticeps podem consumir em relação à quantidade disponível de presas, e as relações entre o seu consumo e crescimento, tendo como presa lagartas de $2^{\circ}, 3 \stackrel{\circ}{\circ}, 4^{\circ}$ e $5^{\circ}$ ínstar de Alabama argillacea (Huebner), foram conduzidos por Silva et al. (1996).

Os fatores que podem interferir no processo de predação são: densidade de presas, densidade de predadores, características do ambiente, mecanismos de defesa da presa, e técnica de ataque do predador (Holling, 1959). Por outro lado, é possível aplicar os princípios nutricionais para aumentar o vigor e a efetividade de inimigos naturais contra as pragas (House, 1977). Portanto, o conhecimento nutricional de $S$. cincticeps, por meio das medidas de consumo e utilização, bem como o efeito da temperatura e defesa da presa, poderão indicar a interação entre o predador e seu recurso alimentar e meio ambiente, fornecendo subsídios para orientar programas de controle biológico de pragas desfolhadoras por meio do $S$. cincticeps.

Sendo assim, procurou-se quantificar, em cada um dos ínstares, o consumo bruto e o consumo diário pelo $S$. cincticeps, tendo como presa larvas de Tenebrio molitor L., com e sem chance de defesa, ganho de peso total e ganho de peso diário pelo $S$. cincticeps, e determinar se a defesa da presa e a temperatura do ambiente afetam o consumo de alimento pelas ninfas de 2o, 3으, 4으 e 5o ínstar de S. cincticeps.

\section{MATERIAL E MÉTODOS}

A pesquisa foi conduzida na Unidade de Controle Biológico (UCB) da Embrapa-Centro Nacional de Pesquisa de Algodão (CNPA), em Campina Grande, $\mathrm{PB}$, durante o período de setembro de 1995 a março de 1996. Os insetos foram mantidos em câmaras climatizadas, a 20,25 e $30^{\circ} \mathrm{C}$, $60 \pm 10 \%$ UR e fotofase de 14 horas.

$\mathrm{Na}$ pesquisa foram utilizados indivíduos de segunda geração do predador $S$. cincticeps e larvas de T. molitor, provenientes das colônias de criação mantidas pela UCB/Embrapa-CNPA.

As ninfas de 1 o ínstar do predador, recém-eclodidas, foram mantidas em placas-de-Petri $(9,0 \times 1,5 \mathrm{~cm})$ até atingirem o $2^{\circ}$ ínstar, e então, individualizadas em copos de plástico de $100 \mathrm{~mL}(4,5 \times 7,5 \mathrm{~cm})$. Na tampa, através de uma abertura de um centímetro de diâmetro, inseriu-se um tubo de vidro tipo anestésico de $2,5 \mathrm{~mL}$, para manter umidade e fornecimento de água aos predadores.

A utilização de ninfas de $S$. cincticeps a partir do 2 ínstar deveu-se ao fato de que as ninfas do 10 ínstar não são predadoras, pois se alimentam de resíduos de ovos e água (Zanuncio et al., 1991).

Foram oferecidas como presas, ao predador, larvas de T. molitor (peso vivo $=112,53 \pm 0,57 \mathrm{mg}$ ) com e sem chance de defesa, sendo que as sem defesa foram oferecidas parcialmente imobilizadas pela inserção de um alfinete entomológico de $0,15 \mathrm{~mm}$, no sentido ventro-dorsal do mesotórax (Silva et al., 1996), visando eliminar a defesa da presa ao ser atacada pelo predador, e as com defesa foram expostas ao predador, sem alfinete.

O delineamento experimental adotado foi inteiramente casualizado, e os tratamentos foram dispostos em esquema fatorial, representados por quatro ínstares do predador, comportamento da presa (larvas de T. molitor com e sem defesa) e três temperaturas constantes: 20,25 , e $30^{\circ} \mathrm{C}$. Os tratamentos foram distribuídos em cinco repetições, sendo cada repetição composta de dez ninfas do predador. Portanto, cada tratamento foi iniciado com 50 ninfas de $2^{\circ}$ ínstar, totalizando 300 ninfas. As ninfas foram individualizadas em copos de plástico, e foi oferecida a cada ninfa, diariamente, uma larva da presa, para avaliação do peso do alimento consumido ( $\mathrm{mg}$ de peso seco).

Para se determinar o peso do alimento consumido diariamente, 50 larvas da presa individualmente foram pesadas, a fim de se obter o peso fresco. O peso seco das larvas foi obtido através da pesagem de uma alíquota de dez larvas, com as mesmas características das larvas utilizadas no estudo, as quais foram pesadas individualmente e levadas à estufa, a $120^{\circ} \mathrm{C}$, durante quatro horas, até atingir peso constante. O peso seco foi estimado pela porcentagem do peso seco médio obtido do peso fresco médio da alíquota. Após 24 horas, foram retiradas as sobras de cada copo e levadas à estufa a $120^{\circ} \mathrm{C}$, colocadas em envelopes de papel-alumínio, para se determinar o peso seco da sobra do alimento. O peso do alimento consumido foi obtido subtraindo-se o peso seco da sobra do alimento do peso seco do alimento fornecido no dia anterior. 
Para se determinar o ganho de peso do predador em um determinado ínstar, subtraiu-se o último peso do predador obtido neste ínstar do peso inicial (início do ínstar).

Os dados obtidos foram submetidos a análises de variância, pelo método PROC GLM (SAS Institute, 1993), e as médias, comparadas pelo teste de Student-NewmanKeuls $(\mathrm{P}=0,05)$.

\section{RESULTADOS E DISCUSSÃO}

Os resultados evidenciaram que o consumo bruto de larvas de $T$. molitor por $S$. cincticeps depende do ínstar do predador e da temperatura $[\mathrm{F}=3,02$ $(\mathrm{P} \leq 0,05)]$, do ínstar do predador e da defesa da presa $[F=28,37(\mathrm{P} \leq 0,05)]$ e da temperatura e defesa da presa $[F=4,81(P \leq 0,05)]$, enquanto o consumo diário depende do ínstar do predador e da temperatura $[\mathrm{F}=5,00(\mathrm{P} \leq 0,05)]$ e do ínstar do predador e da defesa da presa $[\mathrm{F}=12,14(\mathrm{P} \leq 0,05)]$.

$\mathrm{O}$ consumo bruto das larvas de T. molitor por $S$. cincticeps aumentou com a idade do predador nas três temperaturas (Tabela 1), atingindo o máximo, no 5o ínstar. No 2o e 4o ínstar, não houve influência da temperatura, mas no 3o e 5o ínstar verificou-se um consumo maior a $25^{\circ} \mathrm{C}$, isto é, 17,87 e $30,43 \mathrm{mg}$ de peso seco, respectivamente. Comportamento idêntico foi registrado quanto ao consumo diário de $S$. cincticeps, exceto no 2 o e 4o ínstar do predador, em que foi constatado consumo diário maior nas ninfas submetidas a 25 e $30^{\circ} \mathrm{C}$ do que nas que foram expostas a $20^{\circ} \mathrm{C}$ (Tabela 1). No 50 ínstar, o predador apresentou um consumo diário máximo de $5,13 \mathrm{mg}$ sobre as larvas de T. molitor, com peso de $112,53 \mathrm{mg}$, a $25^{\circ} \mathrm{C}$. Nestas mesmas condições térmicas, Silva et al. (1996) registraram 5,48 $\mathrm{mg}$ de consumo diário da presa, quando $S$. cincticeps alimentou-se de lagartas de $A$. argillacea, com peso de 85,23 mg. Do total de alimento consumido pelas ninfas de $S$. cincticeps, mais de $64 \%$ foi consumido durante os dois últimos ínstares. Stamp et al. (1991) verificaram que ninfas de 5o ínstar de Podisus maculiventris (Say), alimentadas com lagartas de Manduca sexta (Fabricius), apresentaram consumo bruto médio de $20 \mathrm{mg}$ a $28^{\circ} \mathrm{C}$, e $38 \mathrm{mg}$ de peso seco a $18^{\circ} \mathrm{C}$. O consumo bruto da presa pelo predador Gerris remigis Say atinge o pico a $19^{\circ} \mathrm{C}$, havendo um declínio acima ou abaixo deste valor (Jamieson \& Scudder, 1977). Quanto aos insetos fitófagos, cerca de $75 \%$ do total do seu alimento é consumido nos últimos ínstares (Waldbauer, 1968). Sabe-se que no 50 ínstar o predador precisa consumir maior quantidade de alimento, a fim de acumular reservas energéticas para a ecdise e para a conversão de parte desta energia em tecidos definitivos do adulto (Stamp et al., 1991).

O consumo bruto de larvas de T. molitor por $S$. cincticeps foi maior quando o predador alimentou-se com larvas sem defesa, a partir do 30 ínstar, aumentando o consumo bruto, com a idade do predador (Tabela 2). Entretanto, no 20 ínstar não houve influência da defesa da presa no consumo do predador. É provável que isto tenha ocorrido em decorrência do tamanho desproporcional das ninfas de

TABELA 1. Consumo bruto e consumo diário de ninfas de 2o, 3o, 4o e 5o ínstar de Supputius cincticeps, tendo como presa larvas de Tenebrio molitor, a 20,25 e $30^{\circ} \mathrm{C}^{1}$.

\begin{tabular}{|c|c|c|c|c|}
\hline \multirow{2}{*}{$\begin{array}{c}\text { Temperatura } \\
\left({ }^{\circ} \mathrm{C}\right)\end{array}$} & \multicolumn{4}{|c|}{ Ínstar } \\
\hline & $2^{\underline{0}}$ & $3^{\underline{0}}$ & $4^{-\mathrm{O}}$ & $5^{\mathrm{o}}$ \\
\hline & & ---- Consumo & to $(\mathrm{mg})$ - -- & \\
\hline 20 & $(82)^{2} 6,81 \pm 0,59 \mathrm{Aa}$ & (60) $11,12 \pm 1,02 \mathrm{Ab}$ & (47) $15,78 \pm 2,45 \mathrm{Ac}$ & (30) $26,13 \pm 4,14 \mathrm{Bd}$ \\
\hline 25 & (70) $9,99 \pm 0,70 \mathrm{Aa}$ & (58) $17,87 \pm 1,57 \mathrm{Bb}$ & (50) $16,96 \pm 1,80 \mathrm{Ab}$ & (42) $30,43 \pm 3,58 \mathrm{Cc}$ \\
\hline 30 & (78) $8,73 \pm 0,70 \mathrm{Aa}$ & (65) $13,03 \pm 1,05 \mathrm{Ab}$ & (53) $17,17 \pm 1,02 \mathrm{Ac}$ & (40) $22,55 \pm 2,47 \mathrm{Ad}$ \\
\hline & & --1----- Consumo d & (mg/dia) - & \\
\hline 25 & (70) $2,29 \pm 0,17 \mathrm{Ba}$ & (58) $4,93 \pm 0,49 \mathrm{Cc}$ & (50) $4,09 \pm 0,40 \mathrm{Bb}$ & (42) $5,13 \pm 0,56 \mathrm{Cc}$ \\
\hline 30 & (78) $2,14 \pm 0,15 \mathrm{Ba}$ & $(65) 3,25 \pm 0,25 \mathrm{Bb}$ & (53) $4,38 \pm 0,27 \mathrm{Bc}$ & (40) $3,84 \pm 0,47 \mathrm{Bbc}$ \\
\hline
\end{tabular}

\footnotetext{
${ }^{1}$ Médias seguidas pela mesma letra, maiúscula nas colunas e minúscula nas linhas, não diferem entre si pelo teste de Student-Newman-Keuls $(\mathrm{P}=0,05)$.
}

2 Número de ninfas. 
2o ínstar $(1,63 \pm 0,11 \mathrm{mg})$ em relação ao da presa $(112,53 \pm 0,57 \mathrm{mg})$. Assim sendo, o tamanho da presa funcionou como defesa ao ataque do predador. Diferenças na quantidade de presas consumidas tornaram-se mais evidentes a partir do 30 ínstar, quando o predador apresentou maior domínio e ataque à presa. Resultados similares foram obtidos quanto ao consumo diário da presa com e sem defesa por ninfas de 2은 $3^{\circ}, 4^{\circ}$ e $5^{\circ}$ ínstar de Supputius cincticeps, exceto quando o consumo diário de presas sem defesa por ninfas de 30 ínstar foi igual ao do 4o ínstar do predador (Tabela 2). No 5o ínstar, o predador apresentou consumo diário maior da presa, ligado ao fato de que neste ínstar o predador necessita de uma quantidade de alimento que corresponda a sua capacidade máxima de consumo, a fim de atingir uma possível saciedade (Silva et al., 1996). P. maculiventris quando tem como presa lagartas de Hyphantria cunea Drury, seleciona a presa em função da capacidade de defesa exibida pelas lagartas de 5o ínstar, com um tempo de ataque variável, consumindo maior número de lagartas sem defesa, o que representa $84 \%$ do seu próprio peso para cada lagarta de 5 ínstar atacada (Morris, 1963).

Predadores exercem um importante papel na manutenção da agressividade e vigor das presas, pois as que não estão aptas a se defenderem, serão eliminadas da população, e aquelas com melhor aptidão para se defenderem, sobrevivem e se reproduzem (Price, 1975). Sendo assim, o predador atua como um agente seletivo na evolução da presa, selecionando os indivíduos mais fortes e vigorosos de cada geração. A seleção de presas é feita com técnicas de ataque mais eficazes.

Portanto, predador e presa coevoluem em busca de manter a sobrevivência das espécies. Santos et al. (1995) relataram que $P$. nigrispinus preda maior quantidade de lagartas pequenas de curuquerê-doalgodoeiro do que lagartas grandes, pelo fato de que lagartas de ínstares mais avançados de A. argillacea apresentam maior capacidade de defesa do que as de ínstares iniciais, o que favorece a sobrevivência de lagartas que se encontram nos últimos ínstares, e as ajudam a atingir a forma adulta. Assim, o P. nigrispinus garantirá a sobrevivência de sua presa, e conseqüentemente, sua sobrevivência nos agroecossistemas dos algodoeiros.

O consumo bruto das larvas de T. molitor por $S$. cincticeps foi maior quando as ninfas do predador se alimentaram de larvas sem defesa a 20,25 , e $30^{\circ} \mathrm{C}$ (Tabela 3). Entretanto, pode-se ver que o maior consumo bruto de larvas de T. molitor pelas ninfas do predador ocorreu quando a presa foi constituída de larvas sem defesa a $25^{\circ} \mathrm{C}$. Waldbauer (1968) afirmou que a quantidade de alimento consumido por lagartas de Bombyx varia com a temperatura, e que pequenas mudanças climáticas ou biológicas no meio ambiente poderão afetar significativamente o consumo bruto dos insetos.

Os ganhos de peso total $[\mathrm{F}=3,64(\mathrm{P} \leq 0,05)]$ e diário $[\mathrm{F}=5,00(\mathrm{P} \leq 0,05)]$ dependem do ínstar de $S$. cincticeps, da temperatura ambiente e do tipo de defesa apresentado pelas larvas de T. molitor.

TABELA2. Consumo bruto e consumo diário de ninfas de 2o, 3o, 4o e 5o ínstar de Supputius cincticeps, tendo como presa larvas com e sem defesa de Tenebrio molitor ${ }^{1}$.

\begin{tabular}{|c|c|c|c|c|}
\hline \multirow[t]{2}{*}{ Defesa } & \multicolumn{4}{|c|}{ Ínstar } \\
\hline & $2^{\underline{o}}$ & $3^{\mathrm{o}}$ & $4^{\underline{0}}$ & $5^{\mathrm{O}}$ \\
\hline Com & $(118)^{2} 8,33 \pm 0,59 \mathrm{Aa}$ & (95) $11,97 \pm 1,12 \mathrm{Ab}$ & $\begin{array}{l}\text { bruto }(\mathrm{mg}) \text { - } \\
(83) 12,15 \pm 0,92 \mathrm{Ab}\end{array}$ & (65) $17,62 \pm 1,05 \mathrm{Ac}$ \\
\hline Sem & (112) $8,69 \pm 0,68 \mathrm{Aa}$ & (88) $16,04 \pm 1,13 \mathrm{Ab}$ & (67) $21,12 \pm 0,85 \mathrm{Bc}$ & (47) $35,12 \pm 2,21 \mathrm{Bd}$ \\
\hline Com & (118) $1,86 \pm 0,15 \mathrm{Aa}$ & (95) $2,86 \pm 0,35 \mathrm{Ab}$ & $\begin{array}{l}\text { rio }(\mathrm{mg} / \mathrm{dia}) \text { - } \\
\quad(83) 2,85 \pm 0,33 \mathrm{Ab}\end{array}$ & (65) $2,72 \pm 0,26 \mathrm{Ab}$ \\
\hline Sem & (112) $2,00 \pm 0,17 \mathrm{Aa}$ & (88) $4,02 \pm 0,41 \mathrm{Bb}$ & $(67) 4,57 \pm 0,20 \mathrm{Bb}$ & (47) $5,16 \pm 0,39 \mathrm{Bc}$ \\
\hline
\end{tabular}


O ganho de peso total de $S$. cincticeps foi maior durante o 5 ínstar, quando teve como presa larvas com ou sem defesa de $T$. molitor a 20,25 , e $30^{\circ} \mathrm{C}$, variando de 5,23 a 8,26 mg (Tabela 4). Estes valores estão de acordo com os de Scriber \& Slansky Junior (1981), os quais constataram que os insetos fitófagos crescem, usualmente, mais no penúltimo ( $24 \%$ do crescimento total, variando de 9 a $36 \%$ ) e último ínstar ( $58 \%$ do crescimento total variando de 39 a $85 \%$ ). Constatou-se maior utilização de larvas com e sem defesa de T. molitor por ninfas do 5o ínstar de S. cincticeps a $25^{\circ} \mathrm{C}$ e 20 e $25^{\circ} \mathrm{C}$, respectivamente. Os ganhos de peso total das ninfas do $2^{\circ}, 3^{\circ}$ e $4^{\circ}$ ínstar de $S$. cincticeps tendo como presa larvas com ou sem defesa de $T$. molitor, a 20,25 , e $30^{\circ} \mathrm{C}$, foram semelhantes. É possível que isto tenha ocorrido porque durante estes ínstares o predador geralmente utiliza a energia para sua manutenção e gasta muita energia na busca e no ataque à presa, tanto em larvas com defesa, como em larvas sem defesa, e uma pequena parte é convertida em massa do corpo. Entretanto, verificou-se maior utilização diária de larvas com ou sem defesa de T. molitor por ninfas de $4^{\circ}$ ínstar de $S$. cincticeps a $30^{\circ} \mathrm{C}(0,73 \mathrm{mg})$ ou $25^{\circ} \mathrm{C}$ $(0,50 \mathrm{mg}) ; 30^{\circ} \mathrm{C}(0,63 \mathrm{mg})$ do que a $20^{\circ} \mathrm{C}(0,46 \mathrm{mg})$; $25^{\circ} \mathrm{C}(0,54 \mathrm{mg})$ ou $20^{\circ} \mathrm{C}(0,42 \mathrm{mg})$, respectivamente. Por outro lado, a utilização diária de larvas da presa com ou sem defesa por ninfas de 50 ínstar do predador foi maior a $25^{\circ} \mathrm{C}(1,47 \mathrm{mg})$ ou $25^{\circ} \mathrm{C}(1,04 \mathrm{mg}) ; 30^{\circ} \mathrm{C}$ $(0,91 \mathrm{mg})$, respectivamente, do que a $20^{\circ} \mathrm{C}(0,62 \mathrm{mg})$; $30^{\circ} \mathrm{C}(1,12 \mathrm{mg})$ ou $20^{\circ} \mathrm{C}(0,69 \mathrm{mg})$ (Tabela 5). No $2^{\circ} \mathrm{e}$ 3o ínstar, as ninfas do predador, tendo como presa larvas com ou sem defesa de T. molitor, a 20, 25, e $30^{\circ} \mathrm{C}$, apresentaram ganhos de peso diário semelhantes. Silva et al. (1996) verificaram maior ganho de peso diário de ninfas de 4o ínstar de $S$. cincticeps

TABELA3. Consumo bruto (mg) de ninfas de Supputius cincticeps, tendo como presa larvas com e sem defesa de Tenebrio molitor, a 20,25 e $30^{\circ} \mathrm{C}^{1}$.

\begin{tabular}{lccc}
\hline Defesa & \multicolumn{2}{c}{ Temperatura $\left({ }^{\circ} \mathrm{C}\right)$} & 25 \\
\hline & 20 & $(117) 14,69 \pm 1,21 \mathrm{Ab}$ & $(131) 12,94 \pm 0,92 \mathrm{Ab}$ \\
Com & $(113)^{2} 9,93 \pm 0,88 \mathrm{Aa}$ & $(103) 22,94 \pm 2,64 \mathrm{Bb}$ & $(105) 17,80 \pm 1,83 \mathrm{Ba}$ \\
\hline
\end{tabular}

${ }^{1}$ Médias seguidas pela mesma letra, maiúscula nas colunas e minúscula nas linhas, não diferem entre si pelo teste de Student-Newman-Keuls $(\mathrm{P}=0,05)$.

2 Número de ninfas.

TABELA4. Ganho de peso total ${ }^{1}$ de ninfas de 2o, 3o, 4o e 5o ínstar de Supputius cincticeps, tendo como presa larvas com e sem defesa de Tenebrio molitor a 20,25 e $30^{\circ} \mathrm{C}^{2}$.

\begin{tabular}{|c|c|c|c|c|c|c|}
\hline \multirow[t]{2}{*}{ Ínstar } & \multicolumn{3}{|c|}{ Com defesa } & \multicolumn{3}{|c|}{ Sem defesa } \\
\hline & $20^{\circ} \mathrm{C}$ & $25^{\circ} \mathrm{C}$ & $30^{\circ} \mathrm{C}$ & $20^{\circ} \mathrm{C}$ & $25^{\circ} \mathrm{C}$ & $30^{\circ} \mathrm{C}$ \\
\hline
\end{tabular}
$2^{\mathrm{o}} \quad(40)^{3} 0,25 \pm 0,02 \mathrm{Aa} \quad(36) 0,20 \pm 0,03 \mathrm{Aa} \quad(42) 0,28 \pm 0,01 \mathrm{Aa} \quad$ (42) $0,27 \pm 0,01 \mathrm{Aa} \quad$ (34) $0,37 \pm 0,03 \mathrm{Aa} \quad(36) 0,25 \pm 0,02 \mathrm{Aa}$

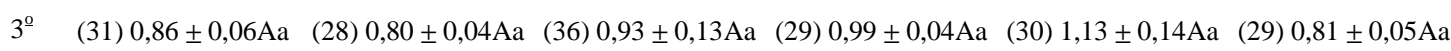

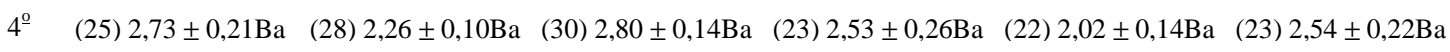
$\begin{array}{llllllll}5^{\circ} & (17) 5,46 \pm 0,67 \mathrm{Ca} & (25) 8,26 \pm 0,32 \mathrm{Cc} & (23) 6,93 \pm 0,60 \mathrm{Cb} & \text { (13) } 6,26 \pm 0,58 \mathrm{Cb} & \text { (17) } 6,40 \pm 0,44 \mathrm{Cb} & \text { (17) } 5,23 \pm 0,43 \mathrm{Ca}\end{array}$

\footnotetext{
${ }^{1}$ Peso seco (mg).

${ }^{2}$ Médias seguidas pela mesma letra, maiúscula nas colunas e minúscula nas linhas, não diferem entre si pelo teste de Student-NewmanKeuls $(\mathrm{P}=0,05)$.

3 Número de ninfas.
} 


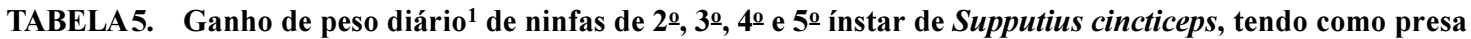
larvas com e sem defesa de Tenebrio molitor a 20,25 e $30^{\circ} \mathrm{C}^{2}$.

\begin{tabular}{|c|c|c|c|c|c|c|}
\hline \multirow[t]{2}{*}{ Ínstar } & \multicolumn{3}{|c|}{ Com defesa } & \multicolumn{3}{|c|}{ Sem defesa } \\
\hline & $20^{\circ} \mathrm{C}$ & $25^{\circ} \mathrm{C}$ & $30^{\circ} \mathrm{C}$ & $20^{\circ} \mathrm{C}$ & $25^{\circ} \mathrm{C}$ & $30^{\circ} \mathrm{C}$ \\
\hline $2^{\underline{o}}$ & $(40)^{3} 0,05 \pm 0,01 \mathrm{Aa}$ & (36) $0,04 \pm 0,01 \mathrm{Aa}$ & (42) $0,07 \pm 0,01 \mathrm{Aa}$ & (42) $0,05 \pm 0,01 \mathrm{Aa}$ & (34) $0,08 \pm 0,01 \mathrm{Aa}$ & (36) $0,06 \pm 0,01 \mathrm{Aa}$ \\
\hline $3^{-0}$ & (31) $0,15 \pm 0,02 \mathrm{Aa}$ & (28) $0,21 \pm 0,01 \mathrm{Ba}$ & (36) $0,23 \pm 0,03 \mathrm{Ba}$ & (29) $0,19 \pm 0,01 \mathrm{Ba}$ & (30) $0,34 \pm 0,05 \mathrm{Ba}$ & (29) $0,20 \pm 0,02 \mathrm{Ba}$ \\
\hline $4^{-}$ & (25) $0,46 \pm 0,04 \mathrm{Ba}$ & (28) $0,54 \pm 0,03 \mathrm{Ca}$ & (30) $0,73 \pm 0,02 \mathrm{Cb}$ & (23) $0,42 \pm 0,05 \mathrm{Ca}$ & (22) $0,50 \pm 0,05 \mathrm{Cab}$ & (23) $0,63 \pm 0,06 \mathrm{Cb}$ \\
\hline $5^{\mathrm{o}}$ & (17) $0,62 \pm 0,08 \mathrm{Ca}$ & (25) $1,47 \pm 0,09 \mathrm{Dc}$ & (23) $1,12 \pm 0,09 \mathrm{Db}$ & (13) $0,69 \pm 0,09 \mathrm{Da}$ & (17) $1,04 \pm 0,06 \mathrm{Db}$ & (17) $0,91 \pm 0,06 \mathrm{Db}$ \\
\hline
\end{tabular}

1 Peso seco (mg/dia).

2 Médias seguidas pela mesma letra, maiúscula nas colunas e minúscula nas linhas não diferem entre si pelo teste de StudentNewman-Keuls $(\mathrm{P}=0,05)$.

3 Número de ninfas.

submetidas a $25^{\circ} \mathrm{C}$ e alimentadas com lagartas de curuquerê-do-algodoeiro com peso médio de $85,23 \mathrm{mg}$ ou $197,74 \mathrm{mg}$, enquanto as ninfas de 50 ínstar tiveram maior ganho de peso diário, quando foram alimentadas com lagartas de $A$. argillacea, com peso médio de $197,74 \mathrm{mg}$.

\section{CONCLUSÕES}

1. O consumo bruto das larvas de T. molitor por $S$. cincticeps depende do ínstar do predador e da temperatura, do ínstar do predador e da defesa da presa, e da temperatura e defesa da presa.

2. O consumo diário das larvas de T. molitor por $S$. cincticeps, depende do ínstar do predador e da temperatura, e do ínstar do predador e da defesa da presa.

3. O ganho de peso de $S$. cincticeps depende do seu ínstar, da temperatura e da defesa apresentada pelas larvas de T. molitor.

4. O tamanho da presa (larvas de T. molitor) funciona como defesa ao ataque de $S$. cincticeps.

\section{AGRADECIMENTOS}

À Coordenação de Aperfeiçoamento do Pessoal de Nível Superior (CAPES) e ao Conselho Nacional de Desenvolvimento Científico e Tecnológico (CNPq), pela concessão de bolsas e auxílio financeiro para realização desta pesquisa.

\section{REFERÊNCIAS}

GRAVENA, S.; CUNHA, H.F. da. Artrópodos predadores na cultura algodoeira. Jaboticabal: UNESP-CEMIP, 1991. 45p. (Boletim, 1).

HOLLING, C.S. Some characteristics of simple types of predation and parasitism. Canadian Entomologist, v.91, n.7, p.385-398, 1959.

HORN, D.J. Ecological approach to pest management. New York: The Guilford Press, 1988. 285p.

HOUSE, H.L. Nutrition of natural enemies. In: RIDGWAY, R.L.; VINSON, S.B. Biological control by augmenting of natural enemies. New York: Plenum Press, 1977. p.151-182.

JAMIESON, G.S.; SCUDDER, G.G.E. Food consumption in Gerris (Hemiptera). Oecologia, v.30, p.23-41, 1977.

MORRIS, R.F. The effect of predator age and prey defence on functional response of Podisus maculiventris (Say) to the density of Hypantria cunea Drury. Canadian Entomologist, v.95, p.1009-1020, 1963.

PRICE, P.W. Insect ecology. New York: John Willey \& Sons, 1975. 514p.

SANTOS, T.M. dos; SILVA, E. do N.; RAMALHO, F. de S. Desenvolvimento ninfal de Podisus connexivus Bergroth (Hemiptera:Pentatomidae) alimentado com curuquerê-do-algodoeiro. Pesquisa Agropecuária Brasileira, Brasília, v.30, n.2, p.163-167, fev. 1995. 
SAS INSTITUTE. SAS User's guide: statistics. Cary, NC, 1993. 584p.

SCRIBER, J.M.; SLANSKY JUNIOR, J.R. The nutricional ecology of immature insects. Annual Review of Entomology, v.26, p.183-211, 1981.

SILVA, E. do N.; SANTOS, T.M. dos; RAMALHO, F. de S. Desenvolvimento ninfal de Supputius cincticeps Stäl (Hemiptera:Pentatomidae) alimentado com curuquerê-do-algodoeiro. Anais da Sociedade Entomológica do Brasil, v.25, p.103-108, 1996.

STAMP, N.E.; ERSKINE, T.; PARADISE, C.J. Effects of rutin fed caterpillars on an invertebrate predator. Oecologia, v.88, p.289-295, 1991.
WALDBAUER, G.P. The consumption and utilization of food by insects. Advances in Insect Physiology, v.5, p.229-288, 1968.

ZANUNCIO, J.C.; NASCIMENTO, E.C.; SANTOS, G.P.; ARAÚJO, F.S. Aspéctos biológicos do predador Podisus connexivus Bergroth, 1891 (Hemiptera:Pentatomidae). Anais da Sociedade Entomológica do Brasil, v.20, p.243-249, 1991.

ZANUNCIO, T.V.; MOREIRA, L.A.; ZANUNCIO, J.C.; SANTOS, G.P. Efeito da densidade ninfal na viabilidade ninfal de Supputius cincticeps Stal, 1860 (Hemiptera:Pentatomidae) criado em laboratório com larvas de Tenebrio molitor (Coleoptera: Tenebrionidae). Revista Brasileira de Entomologia, v.37, p.483-487, 1993. 